\title{
Fachärztemangel
}

\section{Geld versenkt beim Praxisverkauf}

\author{
Im Vergleich zu den Verhältnissen in anderen Fachgruppen \\ gibt es für Hautärzte, die aus Altersgründen ihre Praxis \\ aufgeben wollen und einen geeigneten Nachfolger \\ suchen, derzeit noch keine Probleme. Dies wird sich jedoch \\ schon bald ändern, folgt man den Ergebnissen einer Studie \\ der KBV. Mit dem Ärztemangel gehen Versorgungsmängel \\ für die Bevölkerung einher, er hat aber auch direkte Aus- \\ wirkungen auf den Verkaufswert Ihrer Praxis.
}

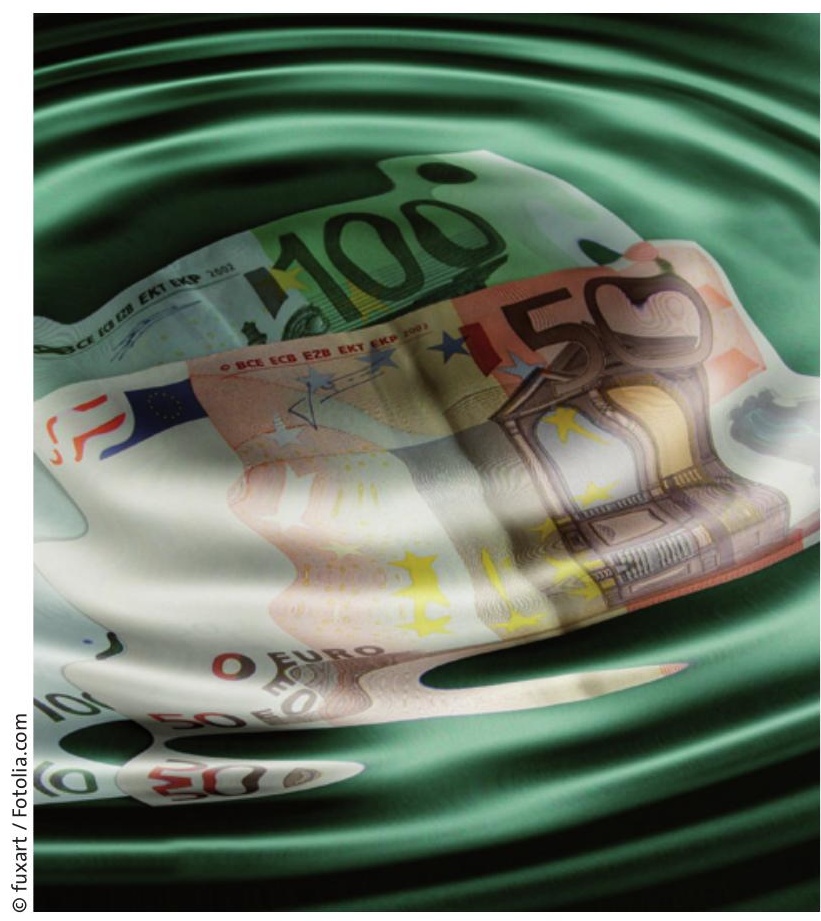

Bundesdurchschnitt über 50 Jahre alt (46,89\%); der Anteil der Ärzte über 60 Jahre liegt in den alten Bundesländern $(11,66 \%)$ niedriger als in den neuen Bundesländern (13,48\%). Parallel zum Anstieg des Durchschnittsalters sinkt der Anteil der unter 35-jährigen Ärzte an allen berufstätigen Ärzten (2009: $16,6 \%)$.

Ärztemangel gibt es auch in den Krankenhäusern. Dort können derzeit 5.000 Stellen nicht besetzt werden. Auch hier wird sich die angespannte Personalsituation schon mittelfristig weiter verschärfen. In den nächsten 10 Jahren gehen fast 20.000 Ober- und Chefärzte in den Krankenhäusern altersbedingt in den Ruhestand. Die Krankenhäuser werden auf dem ärztlichen Nachwuchsmarkt als Konkurrenten für die niedergelassenen Ärzte auftreten.

\section{In zehn Jahren sind Ärzte und Pflegekräfte Mangelware}

Nach der aktuellen Studie zum „Fachkräftemangel im Gesundheitswesen“ könnten in zehn Jahren nicht weniger als 56.000 Ärzte und 140.000 Pflegesowie nicht-ärztliche Fachkräfte fehlen. Die Versorgungslage wird durch die demographische Entwicklung und die Entwicklung des medizinischen Fortschritts nachhaltig beeinflusst. Immer weniger speziell ausgebildete Ärzte ste- hen einer aufgrund der demographischen Entwicklung stetig größer werdenden Patientenschar gegenüber, warnt der Präsident des Berufsverbandes Orthopädie und Unfallchirurgie, Helmut Mälzer.

\section{Lange vor dem Ruhestand:}

\section{Praxisübergabe sorgfältig planen}

Der Ärztemangel verschiebt bei der Übergabe der Praxis an einen Nachfolger grundlegend das Verhältnis zwischen Angebot und Nachfrage. Die Fachärzte für Hautkrankheiten müssen damit rechnen, ganz persönlich ungünstige Auswirkungen des Ärztemangels zu erleben, wenn es ihnen nicht gelingt, bei dem Übergang in den Ruhestand einen geeigneten Nachfolger für das Unternehmen zu gewinnen, der bereit ist, einen angemessenen Preis für die Praxisübernahme zu zahlen. Mit den Vorbereitungen zur Praxisübergabe kann der Unternehmer Arzt daher nicht früh genug starten. Das Vertragsarztrechtsänderungsgesetz vermittelt verschiedene Handlungsoptionen für die Praxisübergabe, die es dem Facharzt ermöglichen, für sein Unternehmen eine maßgeschneiderte „Ausstiegskonzeption" zu entwickeln. Zu erwähnen sind hier insbesondere die Möglichkeiten des Job-Sharings sowie die Führung des Unternehmens mit zwei Teil-Zulassungen. 